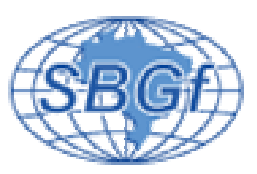

\title{
GEOFÍSICA APLICADA A ESTUdOS DE LAGOS EM ÁREAS URBANAS
}

Luiz Antonio Pereira de Souza *; Antonio Marrano * Wilson Shoji lyomasa *

* Instituto de Pesquisas Tecnológicas do Estado de São Paulo - IPT

Copyright 2004, SBGf - Sociedade Brasileira de Geofísica

Este texto foi preparado para a apresentação no I Simpósio de Geofísica da Sociedade Brasileira de Geofísica, São Paulo, 26-28 de setembro de 2004. Seu conteúdo foi revisado pela Comissão Tecno-científica do I SR-SBGf mas não necessariamente representa a opinião da SBGf ou de seus associados. E proibida a reprodução total ou parcial deste material para propósitos comerciais sem prévia autorização da SBGf.

\section{Resumo}

Este artigo apresenta resultados da utilização de métodos geofísicos na investigação do Lago Guaraciaba, no município de Santo André, Estado de São Paulo, com vistas a subsidiar estudo de planejamento de uso e ocupação de área urbana. Além disso, foram realizados levantamentos geológicos e geotécnicos necessários à análise de estabilidade dos taludes do entorno do lago. Tais estudos visaram encontrar solução tecnológica para evitar ocorrências de acidentes fatais no referido lago. Nesse sentido, foram avaliadas três hipóteses: esvaziamento; aterramento e composição das duas soluções. Ao final do estudo, recomendou-se o esvaziamento parcial do lago e o aterramento das regiões mais profundas, em decorrência das características geológico-geotécnicas locais.

\section{Introdução}

$\mathrm{Na}$ investigação de áreas submersas, os métodos geofísicos têm, em especial, grande importância, haja vista a natural dificuldade de acesso aos locais de interesse por meio da observação direta ou dos métodos convencionais de investigação. No caso do estudo de lagos, principalmente em áreas urbanas, os métodos sísmicos, em particular, ocupam papel relevante, viabilizando, de modo rápido e preciso, a caracterização da superfície de fundo e da subsuperfície do lago, subsidiando estudos ambientais para diversos propósitos. Exemplos de utilização de métodos geofísicos na investigação de reservatórios naturais e artificiais podem ser vistos em SOUZA (1998), SOUZA et al. (1997), IPT (2003). Neste artigo, será enfocado o estudo desenvolvido no Lago Guaraciaba (SP).

\section{Área de estudos e objetivos}

O Parque Guaraciaba, situado no município de Santo André, cerca de $20 \mathrm{~km}$ ao norte da escarpa da Serra do Mar, ainda na Região Metropolitana de São Paulo (Figura 1), constitui-se numa área verde com aproximadamente $550.000 \mathrm{~m}^{2}$, dos quais cerca de $72.200 \mathrm{~m}^{2}(13 \%)$ correspondem a um lago artificial, formado em decorrência de antiga exploração de areia extraída por meio de desmonte hidráulico. Atualmente, o lago e seu entorno são utilizados para atividades de lazer pela comunidade local.

Em decorrência de denúncias de acidentes fatais com banhistas, a Prefeitura Municipal de Santo André, gestora do Parque, foi instada a tomar medidas para evitar a ocorrência de novos acidentes. Para tanto, realizou-se estudo geológico-geotécnico na área do lago e do seu entorno imediato, de modo a subsidiar o desenvolvimento de um plano de uso e ocupação da área. Assim, procedeu-se a análise geológico-geotécnica expedita das encostas marginais para a avaliação da estabilidade dos taludes e a caracterização, por meio de métodos geofísicos, da superfície de fundo e da subsuperfície do lago, definindo-se a distribuição das espessuras da coluna d'água (batimetria) e dos pacotes de sedimentos inconsolidados que cobrem as antigas cavas de mineração. Ecobatimetria, sonografia e perfilagem sísmica contínua foram os métodos geofísicos utilizados na investigação do lago. A opção por estes métodos levou em consideração a rapidez na execução das atividades de campo, bem como a possibilidade de ampla e detalhada cobertura da área de interesse, por meio da aquisição contínua de registros (perfis e imagens) da superfície de fundo do lago.

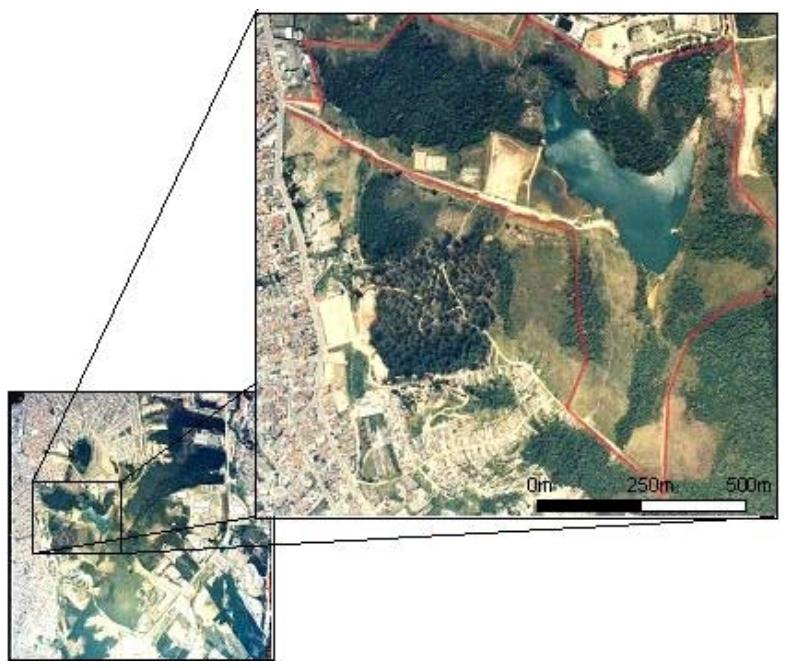

Figura 1: Área do Parque Guaraciaba (em vermelho) no detalhe da foto aérea.

\section{Fundamentos dos métodos geofísicos utilizados}

A investigação de áreas submersas para estudos de assoreamento ou para a implantação de obras como barragens, portos, pontes, plataformas exploratórias ou mesmo para a locação de áreas favoráveis ao posicionamento de cabos e dutos subaquáticos ou rotas de navegação, envolve estudos de subsuperfície que utilizam métodos diretos, como sondagens mecânicas e coleta de amostras de fundo, e métodos indiretos ou geofísicos, a se destacar, a perfilagem sísmica contínua, a sonografia, além da tradicional ecobatimetria (SOUZA, 1998; SOUZA et al., 1998). 


\section{Sonografia}

A sonografia constitui-se num método de investigação de áreas submersas que se baseia nos princípios da reflexão do sinal acústico, utilizando espectros de alta freqüência (normalmente entre $100 \mathrm{kHz}$ e $500 \mathrm{kHz}$ ) e tem por objetivo o mapeamento da superfície de fundo, em substituição às técnicas usualmente utilizadas no mapeamento em terra, como a fotografia aérea, imagens de satélite e de radar, que não são aplicáveis no mapeamento de superfícies submersas, tendo em vista a forte atenuação dos sinais luminosos na coluna d'água. O princípio da sonografia está baseado na emissão de um sinal acústico de alta freqüência, em intervalos de tempo regulares, por meio de transdutores submersos (sonar), que apontam para ambos os lados da superfície de fundo em relação ao rumo da navegação (Figura 2). Os mesmos transdutores de emissão do sinal acústico são também responsáveis pela recepção do sinal, oriundos da reflexão na superfície de fundo e atuam independentemente um do outro.

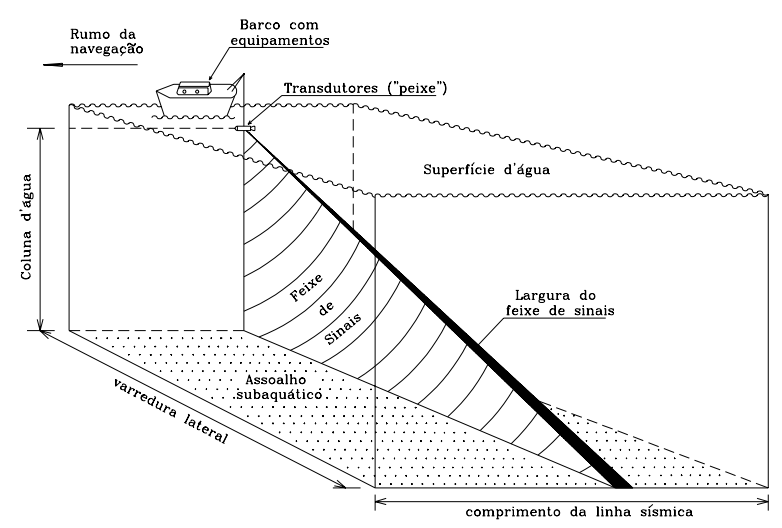

Figura 2: Princípio do método de sonografia (SOUZA, 1988).

O sinal acústico de alta freqüência emitido pelo sonar de varredura lateral, não penetra nos estratos sedimentares, tendo em vista a alta freqüência emitida, porém permite, por outro lado, a obtenção de informações detalhadas da subsuperfície de fundo, possibilitando a identificação de estruturas sedimentares e contatos litológicos com grande precisão. A geometria dos registros de campo obtidos por meio da sonografia está ilustrada na Figura 3. Os registros de campo são denominados sonogramas; alguns exemplos estão ilustrados na Figura 4.

\section{Perfilagem sísmica contínua}

A perfilagem sísmica contínua baseia-se também no princípio da reflexão das ondas acústicas e constitui-se num método indireto de investigação de áreas submersas rasas. Ao contrário da sonografia, utiliza espectros de baixa freqüência (comumente abaixo de $10 \mathrm{Khz}$ ) o que possibilita a penetração do sinal na superfície de fundo,

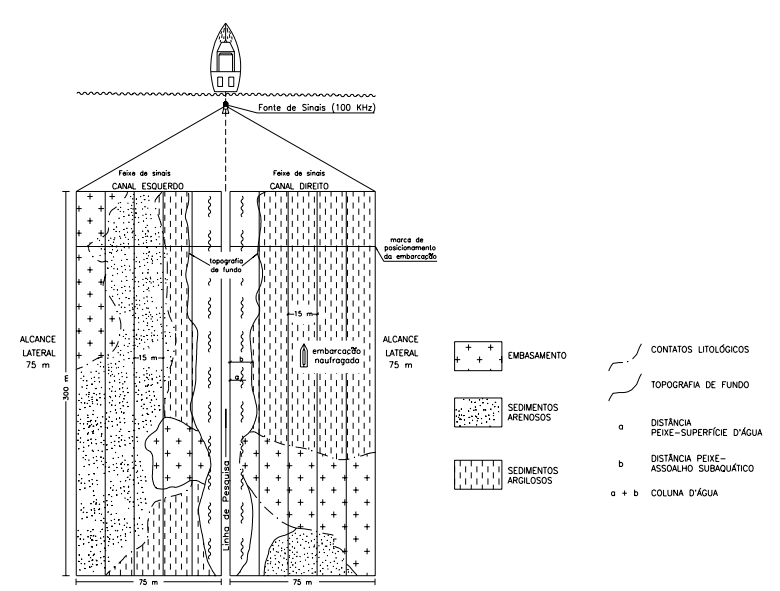

Figura 3: Geometria do registro de campo obtido por meio da sonografia (SOUZA, 1988).

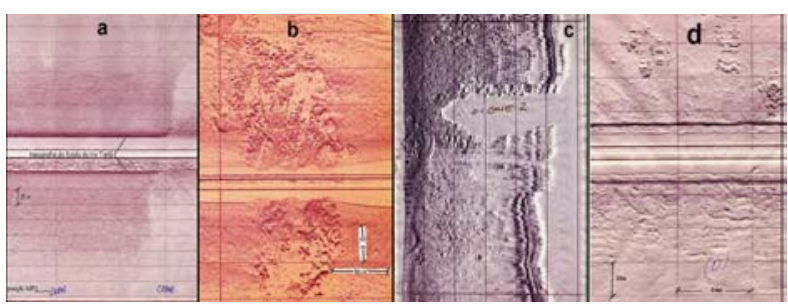

Figura 4: Registros obtidos por meio da sonografia, ilustrando distintos padrões texturais de superfícies de fundo:(a) textura homogênea e lisa representando fundo com sedimentos rio Tietê, SP; (b) textura mista: rugosa na porção central, representando um afloramento de rocha alcalina no canal da Ilha Comprida, SP e lisa e homogênea, nas porções adjacentes ao afloramento, correlacionada a sedimentos marinhos arenosos;(c) textura rugosa relacionada ao fundo rochoso (basaltos) do rio Paraná, à jusante do reservatório de Porto Primavera - na porção superior da figura observa-se a presença de um dique; (d) textura homogênea de um trecho do fundo do mar no litoral do Paraná - as rugosidades texturais na porção superior da imagem representam recifes artificiais.

permitindo, portanto, a identificação da espessura das camadas de sedimentos inconsolidados. Explora a existência de contrastes de impedância acústica entre os diferentes meios físicos subjacentes à superfície de fundo. Por investigação rasa, entende-se profundidades da coluna d'água e espessuras de sedimentos inferiores a $100 \mathrm{~m}-150 \mathrm{~m}$. O sistema de aquisição de dados é composto basicamente de uma fonte repetitiva de sinais sísmicos com características específicas para atuar na água (boomers, sparkers, airguns etc.), um sistema de recepção do sinal sísmico (hidrofones), que são rebocados na superfície da água, e um sistema de gravação, processamento e impressão dos dados, que é instalado no interior da embarcação (Figura 5). 


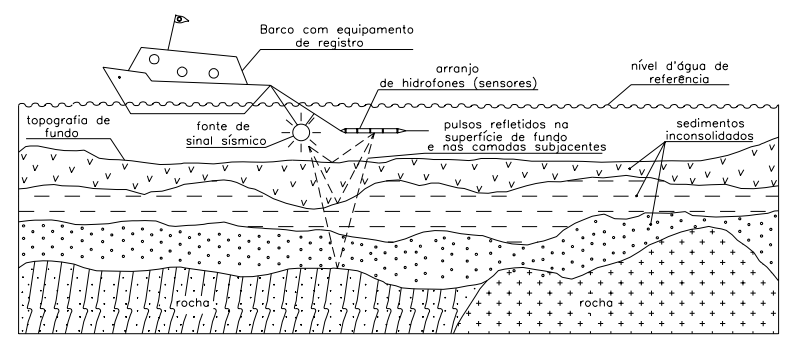

Figura 5: Perfilagem sísmica contínua: geometria do arranjo sensores (hidrofones) (SOUZA, 1988).

As frentes de ondas acústicas emitidas pela fonte propagam-se na água e nos estratos sedimentares subjacentes. Quando da ocorrência de contrastes de velocidade de propagação e de densidade, ou seja, de impedância acústica (velocidade $x$ densidade) entre dois estratos, parte da energia das frentes de onda é refletida na interface entre os mesmos e retorna à superfície, onde é captada por sensores (hidrofones), sendo conduzida ao sistema de processamento e gravação, para finalmente ser impressa em papel eletrossensível ou gravada na forma digital.

\section{Contexto geológico e geomorfológico regional}

O Parque Guaraciaba (PMSA, 1990) está inserido no domínio do Complexo Embu, onde ocorrem metarenitos e xistos finos. Na região sul-sudeste, ocorrem xistos gnaissóides, enquanto que na porção norte-noroeste, há o predomínio de rochas metapsamopelíticas (THEODOROVICZ et al., 1991). Na realidade, os metassedimentos do Grupo Açungui (xistos, filitos, quartzitos) estão englobados no denominado Complexo Pilar, sendo que o Complexo Embu, a outra subdivisão do citado Grupo, é constituído principalmente por migmatitos e gnaisses (IPT, 1981; 1981a). Quanto à geomorfologia, o município de Santo André situa-se no Planalto Paulistano (IPT, 1981b), o qual é subdividido, na região, em Colinas de São Paulo, relevo desenvolvido sobre as rochas terciárias da Bacia Sedimentar de São Paulo, e Morraria do Embu, desenvolvido sobre o embasamento proterozóico. A área do Parque Guaraciaba encontra-se próxima ao contato entre essas subunidades de relevo, mas contida na segunda, a Morraria do Embu.

\section{Levantamentos geofísicos}

Para a aquisição dos dados geofísicos, foram utilizados os seguintes equipamentos: Ecobatimetria: Koden Eletrocnics Co. LTD, SRN Echo Sounder, de $200 \mathrm{KHz}$, de fabricação japonesa; Sonografia: Klein Side Scan Sonar, Hydroscan 531, de $100 \mathrm{KHz}$, de fabricação americana; Perfilagem: Sistema Huntec (boomer), canadense, adaptado por IPT/Intergeo; Posicionamento: DGPS Trimble, Modelo Pro-XL, 12 canais, com estação-base instalada na sede do IPT, em São Paulo. Foram adquiridos cerca de $24 \mathrm{~km}$ lineares de perfis geofísicos, distribuídos no lago conforme ilustrado na Figura 6.

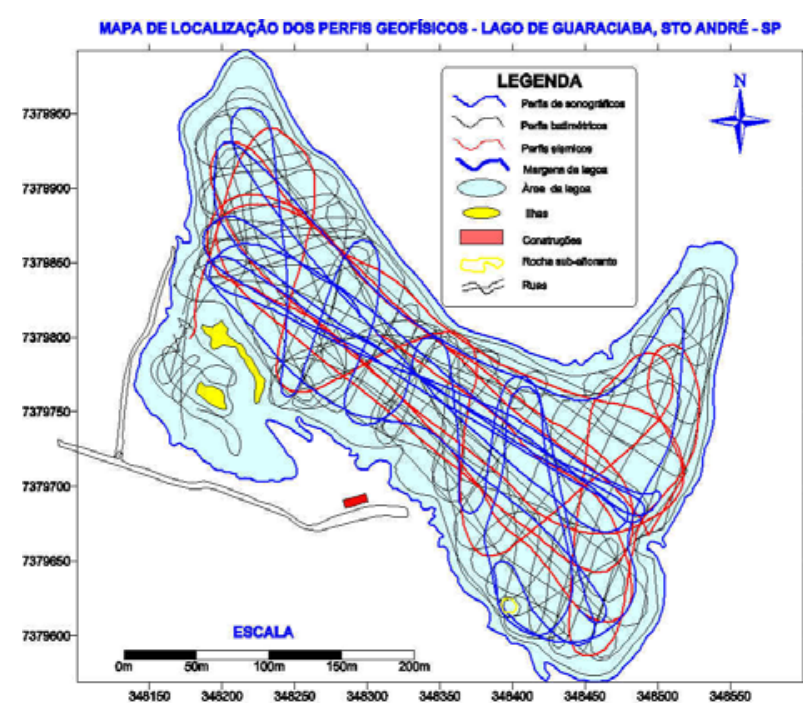

Figura 6: Mapa de localização dos perfis geofísicos executados no Lago Guaraciaba, município de Santo André (SP).

\section{Resultados}

Com base nos dados geofísicos, construiu-se o mapa batimétrico do lago (Figura 7), onde podem ser destacados dois setores distintos, com relação à profundidade, denominados Setor A e Setor B. No primeiro (com cores entre azul e amarelo), a coluna d'água raramente ultrapassa $5 \mathrm{~m}$. Neste setor, conforme atestado pelos registros da perfilagem sísmica contínua (Figura 8), identificaram-se cavas antigas de extração de areia, preenchidas com sedimentos finos até o topo. No setor B (representado no mapa por cores avermelhadas), observa-se que a lâmina d'água é superior à do Setor $\mathrm{A} e$ atinge um máximo de $25 \mathrm{~m}$. Neste setor, as antigas cavas de exploração de areia estão preenchidas apenas em suas porções mais basais (Figura 9).

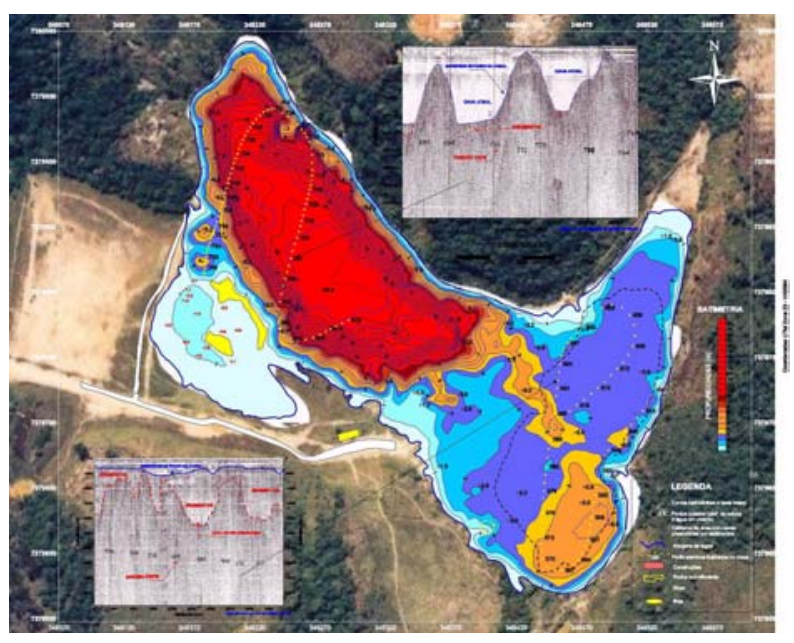

Figura 7: Mapa batimétrico associado à fotografia aérea, mostrando as distintas feições da superfície de fundo do lago. 


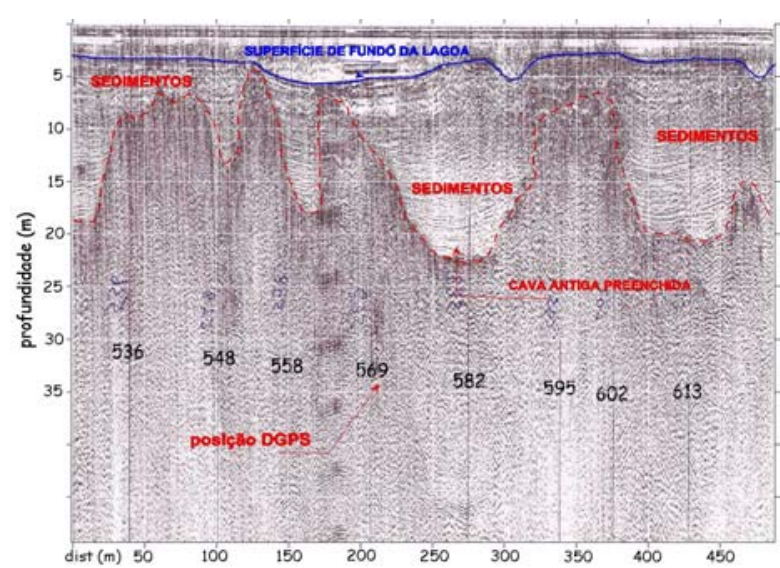

Figura 8: Perfil sísmico mostrando as cavas oriundas da extração de areia, preenchidas por material fino, sismicamente transparente.

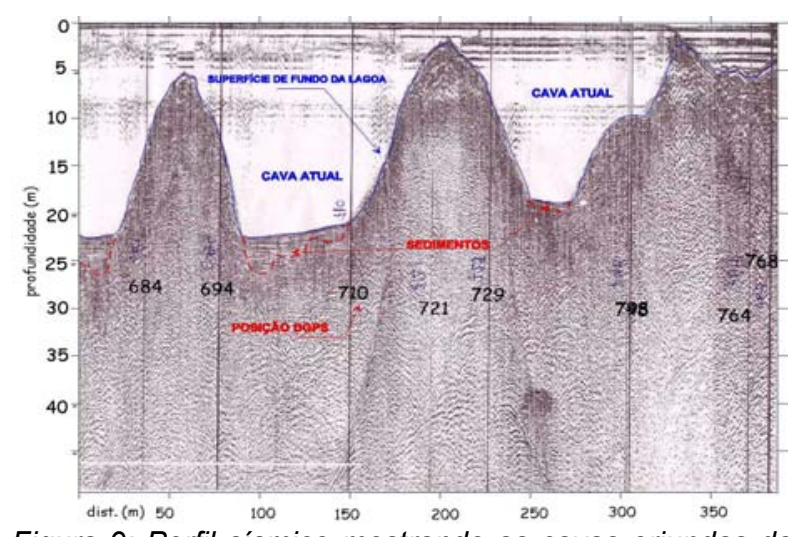

Figura 9: Perfil sísmico mostrando as cavas oriundas da extração de areia, sem preenchimento.

A análise dos dados batimétricos e sísmicos permitiu ainda calcular os volumes totais e parciais do lago (Tabela 1), a diferentes cotas, o que possibilitará, no planejamento de uso e ocupação do lago, o estudo de alternativas de aterramento total ou parcial do lago.

Tabela 1: Volumes de água e sedimentos calculados a partir do levantamento geofísico.

\begin{tabular}{l|c}
\hline \multicolumn{1}{c|}{ DESCRIÇÃO } & Volume $\left(\mathrm{m}^{3}\right)$ \\
\hline $\begin{array}{l}\text { Volume total do lago } \\
\begin{array}{l}\text { Volume de água do lago abaixo de } 10 \mathrm{~m} \text { de } \\
\text { lâmina d'água }\end{array}\end{array}$ & $192 \mathrm{mil}$ \\
\hline $\begin{array}{l}\text { Volume de água do lago abaixo de } 5 \mathrm{~m} \text { de } \\
\text { lâmina d'água }\end{array}$ & $314 \mathrm{mil}$ \\
\hline $\begin{array}{l}\text { Volume de água do lago abaixo de } 3 \mathrm{~m} \text { de } \\
\text { lâmina d'água }\end{array}$ & $391 \mathrm{mil}$ \\
\hline $\begin{array}{l}\text { Volume de água do lago abaixo de } 2 \mathrm{~m} \text { de } \\
\text { lâmina d'água }\end{array}$ & $448 \mathrm{mil}$ \\
\hline $\begin{array}{l}\text { Volume de sedimentos preenchendo as } \\
\text { cavas do lago }\end{array}$ & $95 \mathrm{mil}$ \\
\hline $\begin{array}{l}\text { Volume de sedimentos preenchendo as } \\
\text { cavas do setor raso (A) }\end{array}$ & $79 \mathrm{mil}$ \\
\hline $\begin{array}{l}\text { Volume de sedimentos preenchendo as } \\
\text { cavas do setor profundo (B) }\end{array}$ & $16 \mathrm{mil}$ \\
\hline
\end{tabular}

\section{Discussão e conclusões}

O levantamento batimétrico indicou que cerca de $45 \%$ da área do lago apresenta profundidades entre $4 \mathrm{~m}$ e $25 \mathrm{~m}$ (Figura 7). Segundo informações obtidas no local, tratase da área onde é maior o índice de acidentes fatais de banhistas. Profundidades inferiores a um metro ocorrem em faixas estreitas, adjacentes às margens do lago, no extremo nordeste e na região sudoeste, junto à via de acesso ao parque. Esta configuração da superfície do fundo do lago é herança do método de extração de areia, por desmonte hidráulico. A porção mais profunda, provavelmente, representa a última frente de exploração. Além disso, a perfilagem sísmica revelou a existência de cavas mais antigas preenchidas, aparentemente, com material fino e inconsolidado (lama), resultante do processo de exploração das cavas vizinhas. As irregularidades abruptas da superfície de fundo do lago e o preenchimento com lama podem constituir-se em armadilha aos banhistas.

O levantamento geológico-geotécnico expedito permitiu caracterizar as condições de estabilidade dos taludes marginais ao lago, bem como diagnosticar alguns problemas relacionados a processos de dinâmica superficial, essencialmente erosão e movimentos de massa, para os quais sugeriram-se medidas corretivas pontuais. Os processos erosivos mais significativos estão associados à rocha xistosa muito alterada, principalmente na margem sul, à concentração de fluxo das águas pluviais e às surgências do nível d'água. Quanto aos processos de movimentos de massa, estes se resumem a escorregamentos em solo e em rocha muito alterada, além de quedas de blocos, ambos intimamente associados às condições estruturais do maciço rochoso, sendo, este último, mais problemático por configurar risco aos usuários dos caminhos de acesso existentes nas encostas.

Baseado nos resultados obtidos nos levantamentos geológico-geotécnico e geofísico, foram apresentadas recomendações para subsidiar o projeto de uso e ocupação da área, de modo a evitar acidentes fatais com banhistas e com os usuários dos caminhos de acesso existentes no entorno do lago. Neste contexto, levantaram-se três hipóteses de intervenção, que requerem obras de engenharia, quais sejam: esgotamento do lago, aterramento do lago e a composição entre estas propostas. Além dessas, uma quarta hipótese corresponderia à manutenção do lago no nível em que se encontra.

A possibilidade de se esgotar o lago, operação que, em princípio, acabaria com o problema de acidentes fatais, demanda alguns cuidados e encerra algumas dificuldades. O rebaixamento do nível d'água deverá ser feito lentamente, segundo taxa determinada pelas propriedades geomecânicas dos maciços rochoso e terroso, que devem ser obtidas por meio de ensaios específicos executados in situ e em amostras coletadas. Este procedimento torna-se necessário para não comprometer a estabilidade das encostas marginais, bem como dos taludes a serem expostos, após o esgotamento. Será, ainda, imprescindível o monitoramento constante e sistemático das encostas durante o processo de rebaixamento, pois a alteração 
das condições hidrogeológicas dos maciços, na maioria das vezes, conduz a instabilizações, especialmente naqueles locais onde existe predisposição, como observado na área.

A principal dificuldade está relacionada ao nível máximo de rebaixamento que se alcançaria. Os dados do mapa batimétrico, conjugados com a análise da topografia da área, indicam que, após o esgotamento, restaria ainda um pequeno lago com aproximadamente $15 \mathrm{~m}$ de profundidade, o qual não poderia ser esgotado por gravidade, por estar abaixo do nível de base local. Outro possível problema está associado à natureza do material de preenchimento das cavas da porção centro-sul do lago, a qual deverá ser investigada para se conhecer suas características geotécnicas (compressibilidade, capacidade de carga etc.), para que se tomem os devidos cuidados quando da ocupação da área, após o rebaixamento.

$\mathrm{Na}$ hipótese de aterramento total do lago, o volume de material necessário poderá superar $600 \mathrm{mil} \mathrm{m}^{3}$, contando-se com o processo de adensamento do material submerso (lama). Tal volume corresponde, aproximadamente, a $50 \mathrm{mil}$ viagens de caminhão basculante (capacidade de $12 \mathrm{~m}^{3}$ ). Após o aterramento, a futura área poderá constituir-se em atrativo para a ocupação, sendo necessárias obras de engenharia para estabilizar as encostas marginais íngremes do atual lago, além de estudos e acompanhamento do processo de adensamento do aterro.

$\mathrm{Na}$ terceira hipótese, optando-se por esgotar parcialmente o lago, deixando-o no nível de base local, e promovendo o preenchimento da região centro-sul, deverá ser realizada acurada avaliação geotécnica do material submerso que constituirá o aterro, de modo a evitar possíveis rupturas junto ao lago remanescente, além de outros problemas associados a recalques causados pelo conseqüente carregamento que deverá sofrer a fundação. Ademais, o tipo de material a ser utilizado no preenchimento deverá ser adequadamente avaliado, sobretudo devido às nascentes existentes e à posição do nível freático local.

No caso de se optar pela manutenção do lago tal como se encontra, é necessário tomar outras medidas legais para evitar acidentes. Mesmo que seja adotada esta alternativa, será necessária a realização de análises da qualidade da água, tanto do lago quanto das drenagens que o alimentam (a sul e a nordeste), bem como o detalhamento da caracterização geológica e geoquímica dos sedimentos de fundo, além das intervenções necessárias para a melhoria da estabilidade dos taludes expostos e para a correção dos processos erosivos já instalados.

Ressalta-se, ainda, que a adoção de qualquer solução que envolva obras de engenharia deverá ser precedida da manifestação dos órgãos ambientais competentes, uma vez que o Parque Guaraciaba está inserido em Área de Proteção Permanente (APP).

Finalmente, destaca-se a importância da utilização de métodos geofísicos para a investigação da porção submersa do lago, pois que permitiram reconhecer a natureza da superfície de fundo do lago, mapear com detalhe a distribuição das profundidades (espessuras da coluna d'água), bem como identificar a coluna sedimentar recente.

\section{Agradecimentos}

Os autores agradecem a Secretaria de Obras e Serviços Urbanos da Prefeitura Municipal de Santo André pela oportunidade de realização deste trabalho.

\section{Referências}

INSTITUTO DE PESQUISAS TECNOLÓGICAS - IPT. 1981. Mapa Geológico do Estado de São Paulo. Nota Explicativa. São Paulo, IPT. vol. I.126 p.

INSTITUTO DE PESQUISAS TECNOLÓGICAS - IPT. 1981a. Mapa Geológico do Estado de São Paulo; escala 1 : 500 000. São Paulo, IPT.

INSTITUTO DE PESQUISAS TECNOLÓGICAS - IPT. 1981b. Mapa Geomorfológico do Estado de São Paulo: escala 1 : 1000 000. São Paulo, IPT. 2v.

INSTITUTO DE PESQUISAS TECNOLÓGICAS - IPT. 2003. Levantamento batimétrico no lago do Parque Guaraciaba e caracterização geológico-geotécnica das encostas marginais, município de Santo André, SP. São Paulo, IPT. 71 p. (IPT Relatório, 66.080).

PREFEITURA MUNICIPAL DE SANTO ANDRÉ. SECRETARIA DE OBRAS E SERVIÇOS URBANOS PMSA. 1990. Levantamento Geológico-Geotécnico. Concurso Nacional de Estudos Preliminares. Santo André, PMSA.

SOUZA, L.A.P. 1988. As técnicas geofísicas de sísmica de reflexão de alta resolução e sonografia aplicadas ao estudo de aspectos geológicos e geotécnicos em áreas submersas. In: CONGRESSO BRASILEIRO DE GEOLOGIA, 35, Belém, 1988. Anais...Belém: Sociedade Brasileira de Geologia. v.4, p.1551-1564.

SOUZA, L.A.P. 1998. Exemplos de utilização de métodos geofísicos na investigação de áreas submersas. In: ENCONTRO REGIONAL DE GEOTECNIA E MEIO AMBIENTE, II / WORKSHOP DE GEOFÍSICA APLICADA, II, Rio Claro, 1998. CD-ROM.

SOUZA, L. A. P.; MELLO, I.S.C., MOTTA, J.F.M. 1997. A utilização de métodos geofísicos na investigação de reservatórios: o exemplo do reservatório de Guarapiranga. In: CONGRESSO INTERNACIONAL DA SOCIEDADE BRASILEIRA DE GEOFÍSICA, 5, São Paulo, 1997. Boletim de Resumos Expandidos: vol. 1, p.430-433.

SOUZA, L.A.P.; SILVA, R. F. da; IYOMASA, W. S. 1998. Métodos de Investigação. In: OLIVEIRA, A. M. S.; BRITO, S. N. A. (ed.). Geologia de Engenharia. São Paulo: ABGE, 1998. cap. 11. (IPT Publicação, 2551).

THEODOROVICZ, A.; YAMATO, A. A.; VASCONCELOS, C. S.; SANTARÉM, P. C.; SILVA, L. C.; SILVA, V. A. 1991. Características litoestruturais do Cinturão de Cisalhamento Transcorrente São Paulo. Região Leste da Grande São Paulo. In: SIMPÓSIO DE GEOLOGIA DO SUDESTE, 2, São Paulo, 1991. Atas...São Paulo:SBG. p. 473-480. 